\title{
Aplicabilidade da radioterapia para carcinoma espinocelular em plano nasal de gatos
}

\section{Applicability of radiotherapy for squamous cell carcinoma in the nasal plane of cats}

\section{Daiana Barros do Carmo}

Tecnóloga em radiologia pela Fasm. Pós graduada em radioterapia pela HCMUSP

E-mail: daycarmo3103@gmail.com

\section{Ruy Neri Robalos da Rosa Júnior.}

Tecnólogo em Radiologia pela Universidade Lutera do Brasil

Instituição: Instituto Internacional de Estudos em Saúde (IIESAU)

\section{RESUMO}

A efetividade da radioterapia para o tratamento do carcinoma de células escamosas do plano nasal é inconsistente. A profundidade da penetração e terapêutica no carcinoma de células escamosas cutâneo em gatos a dose total que pode ser aplicada de forma segura são dependentes do tipo de radiação. Há várias modalidades de tratamento para carcinoma em gatos e cães, incluindo cirurgia, quimioterapia, terapia fotodinâmica e radioterapia. O diagnóstico precoce é essencial, já que as lesões pequenas podem ser erradicadas, assim como o tamanho do tumor e a profundidade da erosão é importante para a determinação do prognóstico.

Palavras-chave: 1 Carcinoma espinocelular, 2 Radioterapia, 3 Plano nasal.

\section{ABSTRACT}

The effectiveness of radiotherapy for the treatment of squamous cell carcinoma of the nasal plane is inconsistent. The depth of penetration and therapy in cutaneous squamous cell carcinoma in cats at the total dose that can be safely applied are dependent on the type of radiation. There are several treatment modalities for carcinoma in cats and dogs, including surgery, chemotherapy, photodynamic therapy and radiation therapy. Early diagnosis is essential, since small lesions can be eradicated, as well as the size of the tumor and the depth of erosion is important for determining the prognosis.

Keywords: 1. Squamous cell carcinoma, 2. Radiotherapy, 3, Nasal plane. 


\section{INTRODUÇÃO}

O carcinoma é considerado uma neoplasia maligna comum em animais e humanos. Há várias modalidades de tratamento para carcinoma em gatos e cães, incluindo cirurgia, quimioterapia, terapia fotodinâmica e radioterapia.

Atualmente o método mais utilizado é com o uso do Acelerador Linear que utiliza fonte de radiação artificial através de raios $x$ de alta energia. Consagrada com tratamento de neoplasias malignas humanas a radioterapia apresenta normalmente uma sobrevida qualificada ao paciente, visando a morte das células neoplásicas evitando sempre atingir as células sadias circunvizinhas.

Uma Radiografia dos Seios Paranasais podendo demonstrar uma possível infecção.

Já a Tomografia Computadorizada é utilizada para identificação de cânceres da cavidade nasal e para guiar precisamente o posicionamento de uma agulha de biópsia ${ }^{2}$.

A ressonância magnética é utilizada para determinar o tamanho e a localização do câncer bem como a presença de metástase.

A biópsia é indicada para avaliação anatomopatológica sendo a PAAF (Punção Aspirativa com Agulha Fina), com o uso de anestésico local utilizada para verificar se o aumento dos gânglios linfáticos contêm a doença.

O animal precisa ser anestesiado, sendo importante salientar que existe sempre um ligeiro risco associado com anestesia geral, embora o animal seja monitorizado cuidadosamente enquanto está anestesiado, sendo anestesia sempre de curta duração.

Antes da radioterapia, cada animal é avaliado através de exames laboratoriais e exame físico, para ser submetido à anestesia. Durante a primeira sessão, o animal é colocado sobre a mesa e são utilizadas as radiografias, exames de ressonância magnética e tomografia computadorizada, por meio das quais se tem a localização exata do tumor.

Nos estágios iniciais do processamento, o veterinário tem de decidir qual método de imagem deve ser utilizado para acompanhamento do tratamento, optando-se pela tomografia computadorizada ou pela imagem de ressonância magnética ${ }^{2}$.. 
A imagem de ressonância magnética pode fornecer informações valiosas, mas possui algumas limitações quando comparado com a tomografia, especialmente no uso do planejamento do tratamento, um exemplo comum é o emprego da dosimetria 1 .

Caso a radioterapia seja utilizada para fins paliativos, o procedimento requer grandes frações, distribuídas uma vez por semana durante três semanas.

Já a curativa é recomendada em várias situações entre elas utiliza-se essa modalidade para esterilizar as margens do campo de um sarcoma como principal tratamento para tumores nasais e faciais e como tratamento primário para alguns tumores cerebrais. Atua no controle local dos tumores orais, é usada também no tratamento pré operatório de sarcoma .

Esses tumores compartilham características clínicas e achados radiográficos similares, variando tipo histológico, local de origem e estágio do tumor no momento de seu diagnóstico ${ }^{2}$.

Devido a pobreza de sintomas que costumam acompanhar os estágios iniciais da doença, o diagnóstico é frequentemente tardio. Esses tumores sejam benignos ou malignos, chegam a estes estágios avançados devido às seguintes razões:

O nariz e os seios paranasais são cavidades preenchidas por ar, limitados por paredes ósseas bastante delgadas, permitindo um crescimento tumoral progressivo que ocupa espaço e deforma lentamente as paredes nasais de forma silenciosa, até tamanhos significantes, antes de causar qualquer sintoma clínico.

\section{EMBASAMENTO TEÓRICO}

A radioterapia é uma das modalidades de tratamento do câncer, e sua principal finalidade é matar as células neoplásicas, evitando atingir o tecido sadio adjacente ${ }^{3}$.

O carcinoma espinocelular também conhecido como (escamoso) o tumor de pele mais frequente em felinos e está relacionado à exposição dos animais aos raios solares e ao clima da região 4-6. 
As áreas com poucos pelos como o plano nasal e pálpebras, são as mais acometidas e gatos brancos são mais propensos do que gatos de outras cores $4,5,6$.

Os gatos de pelagem branca são mais propensos a apresentar a doença que os pigmentados; nesses últimos, o tumor se desenvolve em áreas com pouco pelo e sem pigmento 6 .

Desenvolvimento da neoplasia 6, 8, 9. A maioria das lesões está localizada na cabeça, mais frequentemente no plano nasal, seguida pelas aurículas e pálpebras 8, 7. O dígito pode também ser local de desenvolvimento primário da neoplasia 10. Gatos que apresentam tumores nas pálpebras geralmente têm outros localizados no plano nasal.

O tumor pode ser observado em gatos jovens, mas a média de idade é 11 anos e quatro meses, segundo 6. A afecção pode estar presente por meses ou anos e, em geral, a história clínica está associada à presença de ferimentos que não cicatrizam 7 .

No início as lesões são proliferativas, crostosas e posteriormente evoluem para úlceras com invasão de tecidos adjacentes 6, 9 .

O tumor é localmente agressivo e com baixa taxa de metástase para linfonodos regionais e pulmão 9. Dependendo da localização e extensão, muitas vezes o animal demonstra apenas um pequeno desconforto 10.

Existem várias modalidades de tratamento para o carcinoma de células escamosas, incluindo cirurgia, criocirurgia, radiação ionizante, quimioterapia e terapia fotodinâmica 9. O diagnóstico precoce é essencial, já que as lesões pequenas podem ser erradicadas 11 , assim como o tamanho do tumor e a profundidade da erosão são importantes para a determinação do prognóstico 7 .

A escolha do tratamento é dependente não somente do estadiamento do tumor, mas do grau de aceitação do proprietário com relação aos efeitos colaterais e as mudanças estéticas e da disponibilidade de equipamentos e fármacos 7. 
A meta do tratamento cirúrgico é a remoção de suficiente tecido para deixar as margens cirúrgicas livres de células neoplásicas, ao mesmo tempo em que mantém a função e a estética 10.

A criocirurgia é indicada para tumores superficiais não -invasivos com menos de $0,5 \mathrm{~cm}$ em diâmetro, ou quando a cirurgia não pode ser realizada por limitações anatômicas ou devido à não concordância do proprietário 6 .

A efetividade da radioterapia para o tratamento do carcinoma de células escamosas do plano nasal é inconsistente. A profundidade da penetração e

terapêutica no carcinoma de células escamosas cutâneo em gatos a dose total que pode ser aplicada de forma segura são dependentes do tipo de radiação 11.

Uma das principais desvantagens do método é a necessidade de várias anestesias gerais, já que a dose de radiação deve ser dividida em múltiplos tratamentos 12. Adicionalmente, gatos positivos para o vírus da imunodeficiência felina são mais susceptíveis ao desenvolvimento de toxicidade cutânea 7 .

Figura 1: a) Recidiva da lesão após quatro meses da nosectomia. Fonte: Ciência Rural, v.36, n3, mai-jun, 2006. b) Resposta positiva após início de quimioterapia com doxorubicina e bleomicina. Fonte: Ciência Rural, v.36, n3, mai-jun, 2006.

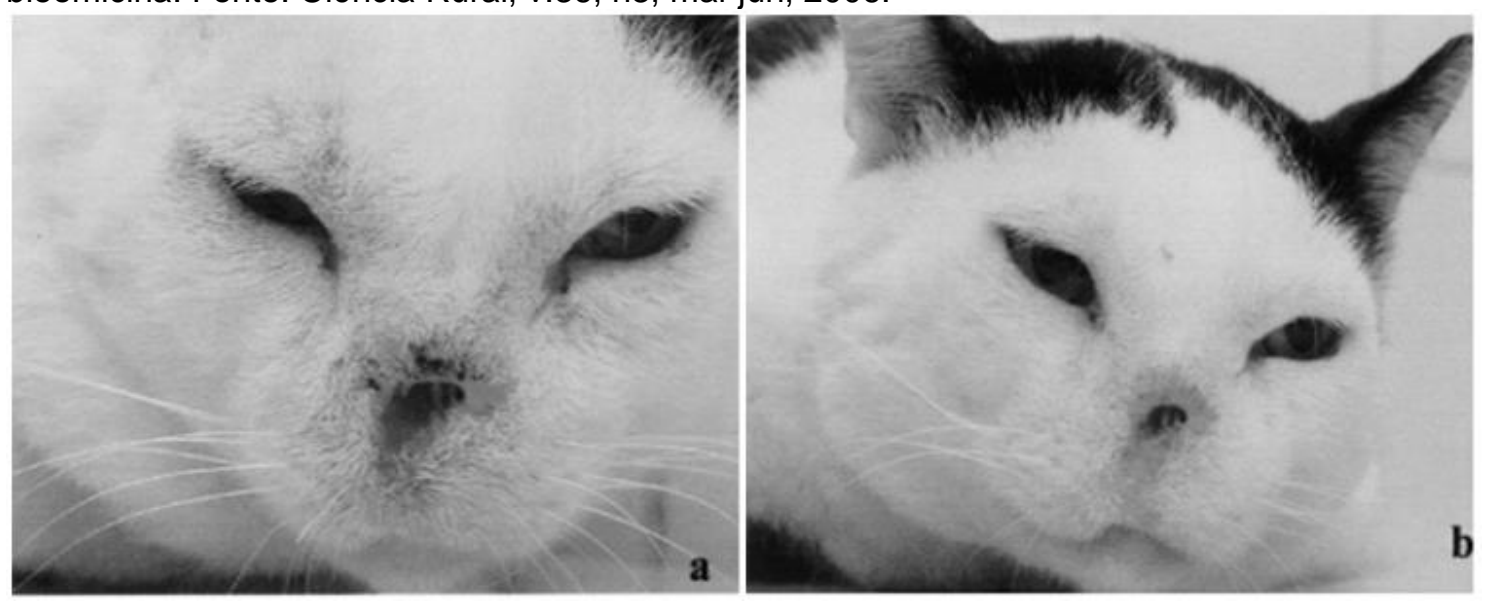

Radiação com feixe de prótons foi aplicada, por 17, em 15 gatos com carcinoma de células escamosas no plano nasal. A média de sobrevivência foi de 946 dias. Os efeitos colaterais foram mínimos, com $60 \%$ de resposta completa, $33 \%$ com resposta parcial e 6,6\% sem nenhuma resposta à terapia. 
A quimioterapia, conforme 7 , não é muito utilizada para o carcinoma cutâneo de células escamosas em gatos. Dois dos fármacos mais efetivos em humanos e cães não são considerados seguros em gatos; a cisplatina pode causar edema pulmonar agudo fatal e o 5-fluorouracilinduz neurotoxicidade 6 . A bleomicina foi empregada por via subcutânea ou intravenosa em quatro gatos com carcinoma de células escamosas, com resposta parcial transitória em três deles 13.

\section{DISCUSSÃO}

A radiação deve ser dividida em múltiplos tratamentos (fracionamento) para melhor controle do tumor e minimização dos efeitos colaterais 14, 15, 7.

No tratamento do CE preconizado em outros países, o animal é submetido à radioterapia três a cinco vezes por semana, sendo anestesiado em cada sessão, o que se torna uma desvantagem, pois os pacientes com câncer em geral são geriátricos e portadores de outras enfermidades.

Utilizou 18 radioterapia de ortovoltagem e megavoltagem com cobalto-60, em 11 gatos com CE do plano nasal. O protocolo utilizado foi de seis a 10 frações de 3,75 a 4,4Gy, três vezes por semana. Houve remissão inicial em todos os animais e recorrência da neoplasia após o tratamento em nove deles. $O$ trabalho não fez referência à taxa de resposta. Aplicaram 15 a ortovoltagem em 90 gatos com CE, utilizando um protocolo de 10 frações de 4gy, três vezes por semana. A taxa estimada de remissão completa foi calculada apenas para estágios T1 (56\%), porém a taxa de resposta geral não foi mencionada. A conclusão mais importante deste trabalho foi que neoplasias iniciais (T1) apresentaram maior taxa de resposta que aquelas em fase avançada (T4).

Usaram 17 um protocolo acelerado com feixe de prótons com energia de $72 \mathrm{MeV}$ e com dose total de 40.4 CGE a 44,8 CGE. Com esse protocolo, obtiveram a taxa de $60 \%$ de remissão completa duradoura e $33 \%$ de remissão parcial nos 15 gatos portadores de CE tratados. Vos et al., 2004 utilizaram a ortovoltagem de $50 \mathrm{kv}$, com um protocolo de 12 frações de $4 \mathrm{gy}$, três vezes por semana, em seis gatos com CE avançado, porém em associação à administração intralesional de carboplatina. A carboplatina era injetada dentro da 
lesão neoplásica, aproximadamente trinta minutos antes de cada sessão radioterápica, com o objetivo de atuar como um agente citotóxico e rádio potencializador. O estudo obteve $100 \%$ de remissão completa, sendo que apenas um animal apresentou recorrência da lesão 174 dias após o tratamento.

Utilizaram 19 um protocolo acelerado de elétrons, de 10 frações de 4,8gy, durante cinco dias consecutivos (com intervalo mínimo entre frações de seis horas), em 17 gatos com CE. O estudo obteve 94\% de resposta completa, e destas, apenas $37,5 \%$ apresentaram recorrência da lesão, ficando o restante sem recorrência até a data limite do estudo.

Protocolos que utilizam aplicações semanais de radioterapia (hipofracionamento) são mais práticos, requerem menor número de procedimentos gerais de anestesia e têm menor custo. No entanto, há poucos estudos na medicina veterinária sobre sua eficácia e segurança. $O$ objetivo deste trabalho foi avaliar a eficácia do tratamento hipofracionado de radioterapia em cinco gatos portadores de carcinomas epidermóides na região da face.

O acompanhamento dos animais foi realizado semanalmente durante 0 tratamento e aos 30 e 60 dias após o término da radioterapia, e as lesões monitoradas quanto à sua evolução, por meio de câmeras fotográficas digitais. A biópsia das lesões que apresentaram regressão completa foi repetida para a confirmação da cura 60 dias após o tratamento.

Apesar de a dose por fração ser extremamente alta quando comparada à de outros protocolos utilizados nesta neoplasia em animais e humanos, o que poderia levar a reações teciduais agudas mais graves, as gatas tratadas neste experimento apresentaram reações leves/moderadas e reversíveis ao tratamento, mostrando que toleram muito bem o tratamento radioterápico. De acordo com a literatura, as reações na pele ocorrem à medida que a radiação se acumula, e as reações cutâneas progridem desde eritema até descamação seca ou úmida e epilação $14,7,16$. O dano tecidual máximo ocorre sete a 14 dias após o tratamento 14. As reações tardias da radiação ocorre meses ou anos após o tratamento radioterápico e incluem despigmentação, alopecia, fibrose, necrose, formação de fístulas, baixa resistência a infecções, conjuntivite crônica, 
ceratoconjuntivite seca e catarata 14, 7, 16. Os efeitos colaterais observados foram leves/moderados e incluíram dermatite, epilação, conjuntivite e rinite, que se resolveram com tratamento de suporte. Não foram observadas reações tardias ao tratamento até a presente data, sendo ainda possível que estas ocorram nos próximos meses ou anos.

Tabela 1. Estadiamento clínico de tumores epidermais dos felinos segundo a Organização Mundial de Saúde*

\begin{tabular}{ccc}
\hline Localização & Estágio & Definição \\
\hline & $\mathrm{T}_{\mathrm{is}}$ & Carcinoma in situ (pré-invasivo) \\
& $\mathrm{T}_{0}$ & Sem evidência de tumor \\
Tumor Primário & $\mathrm{T}_{1}$ & Tumor $<2 \mathrm{~cm}$ de diâmetro, superficial \\
& $\mathrm{T}_{2}$ & Tumor entre $2 \mathrm{e} 5 \mathrm{~cm}$ de diâmetro ou com minima invasão do tecido subcutâneo \\
& $\mathrm{T}_{3}$ & Tumor $>5 \mathrm{~cm}$ de diâmetro ou com invasão do tecido subcutâneo \\
& $\mathrm{T}_{4}$ & Tumor invadindo outras estruturas, como fảscia, músculo, cartilagem ou osso \\
Linfonodos & $\mathrm{N}_{0}$ & Sem evidência de acometimento de linfonodos \\
Regionais & $\mathrm{N}_{1}$ & Acometimento de linfonodos \\
Metástases & $\mathrm{M}_{0}$ & Sem evidência de metástases \\
Distantes & $\mathrm{M}_{1}$ & Evidência de metástases \\
\hline
\end{tabular}

*Owen (1980).

Tabela 2. Perfil, características das lesões neoplásicas, resposta ao tratamento radioterápico e reações agudas de cinco felinos tratados com protocolo hipofracionado de radioterapia

\begin{tabular}{|c|c|c|c|c|c|c|c|}
\hline Gato & Idade & Pelagem & Localizaç̃o das lesð̃es & Estadiamento & Dose & Resposta & $\begin{array}{c}\text { Reação } \\
\text { aguda }\end{array}$ \\
\hline 1 & $\begin{array}{c}10 \\
\text { anos }\end{array}$ & Tricolor & $\begin{array}{c}\text { Nasal } \\
\text { Pálpebra esquerda }\end{array}$ & $\begin{array}{l}\mathrm{T}_{2} \mathrm{~N}_{0} \mathrm{M}_{0} \\
\mathrm{~T}_{1} \mathrm{~N}_{0} \mathrm{M}_{0}\end{array}$ & $\begin{array}{c}4 \text { frações } \\
7,6 \mathrm{gy}\end{array}$ & $\begin{array}{l}\mathrm{RC} \\
\mathrm{RC}\end{array}$ & $\begin{array}{l}\text { Epilação } \\
\text { Conjuntivite }\end{array}$ \\
\hline 2 & $\begin{array}{c}12 \\
\text { anos }\end{array}$ & $\begin{array}{l}\text { Preta e } \\
\text { branca }\end{array}$ & Nasal & $\mathrm{T}_{4} \mathrm{~N}_{0} \mathrm{M}_{0}$ & $\begin{array}{c}4 \text { frações } \\
7,6 \mathrm{gy}\end{array}$ & NR & $\begin{array}{c}\text { Rinite e } \\
\text { dermatite }\end{array}$ \\
\hline 3 & $\begin{array}{c}13 \\
\text { anos }\end{array}$ & Tricolor & $\begin{array}{l}\text { Pálpebra direita } \\
\text { Pálpebra esquerda }\end{array}$ & $\begin{array}{l}\mathrm{T}_{2} \mathrm{~N}_{0} \mathrm{M}_{0} \\
\mathrm{~T}_{1} \mathrm{~N}_{0} \mathrm{M}_{0}\end{array}$ & $\begin{array}{c}4 \text { fraçōes } \\
10 \mathrm{gy}\end{array}$ & $\begin{array}{l}\text { RP } \\
\text { RC }\end{array}$ & $\begin{array}{c}\text { Rinite e } \\
\text { dermatite } \\
\text { Conjuntivite } \\
\text { Conjuntivite }\end{array}$ \\
\hline 4 & $\begin{array}{c}16 \\
\text { anos }\end{array}$ & Branca & $\begin{array}{c}\text { Nasal } \\
\text { Têmpora direita }\end{array}$ & $\begin{array}{l}\mathrm{T}_{3} \mathrm{~N}_{0} \mathrm{M}_{0} \\
\mathrm{~T}_{2} \mathrm{~N}_{0} \mathrm{M}_{0}\end{array}$ & $\begin{array}{c}4 \text { frações } \\
10 \text { gy }\end{array}$ & $\begin{array}{l}\text { RP } \\
\text { RP }\end{array}$ & $\begin{array}{c}\text { Rinite } \\
\text { Dermatite e } \\
\text { epilação }\end{array}$ \\
\hline 5 & $\begin{array}{c}7 \\
\text { anos }\end{array}$ & Branca & $\begin{array}{c}\text { Pavilhão auricular } \\
\text { direito }\end{array}$ & $\mathrm{T}_{2} \mathrm{~N}_{0} \mathrm{M}_{0}$ & $\begin{array}{l}4 \text { frações } \\
7,6 \text { gy }\end{array}$ & RP & Dermatite \\
\hline
\end{tabular}

RC: remissão completa; RP: resposta parcial; NR: ausência de resposta.

\section{CONSIDERAÇÕES FINAIS}

Dentre todas as modalidades de tratamento para cães e gatos, a radioterapia hipofracionada é um método mais eficaz tendo resultados satisfatórios, com menos efeitos colaterais, possibilitando a cura e a melhoria da qualidade de vida do animal. 


\section{REFERÊNCIAS}

[1] CASCIATO, Dennis Albert; LOWITZ, Barry Bennet (Ed.). Manual de oncologia clínica. 2.ed. Rio de Janeiro, RJ: Medsi , 1991. 774.

[2] BARACAT, Fausto Farah; FERNANDES JÚNIOR, HézioJadir; SILVA, Maria José da. Cancerologia atual: um enfoque multidisciplinar. São Paulo, SP: Roca, 2000. 548 ISBN 85-7241-306-5

Hand et al., 2004;

Kent, 2006

Carpenter et al., 1987;

[3] Ruslander, 1997;

[4] Moore e Ogilvie, 2001;

[5] Burrows et al., 1994;

[6] Straw, 1998;

[7] Rogers, 1994;

[8] Thomas e Fox, 2002;

[9] Donner, 1992;

[10] Buhles e Theilen, 1973; Machado, 2000;

[11] MacEwen et al., 1987;

[12] Théon et al., 1995;

[13] Colleen e Mayer, 2006;

[14] Fidel et al., 2001;

[15] Cox (1991);

[16] Melzer et al., 2006;

[17] CUNHA, S. C. S. et al. A utilização da radioterapia no tratamento do carcinoma de células escamosas cutâneo felino avançado. Arquivo Brasileiro de Medicina Veterinária e Zootecnia, v. 66, n. 1, p. 7-14, 2014.

[18] BRAZIL FILHO, Rua Vital. Tratamento hipofracionado de radioterapia em felinos portadores de carcinoma epidermóide facial. Arq. Bras. Med, v. 62, n. 5, p. $1135-1141,2010$. 
[19] GUEDES, Alonso Gabriel Pereira; SHMITT, Isabela; PIPPI, Ney Luis. Dermatite solar felina associada a carcinoma epidermóide. Ciência Rural, v. 28, n. 4, p. 707-713, 1998.

[20] MORETTO, Alice Juliana Godoy; EM RADIOLOGIA, Tecnólogo ; CORREA , Fabrício Gonçalves Radioterapia para Carcinoma em Animais domésticos.

[21]http://faef.revista.inf.br/imagens_arquivos/arquivos_destaque/PEvqrP3jd5M 2D5R_2013-5-20-10-24-2.pdf. 